\title{
Education for UN Sustainable Development Goal 12: A Cross-Curricular Program for Secondary Level Students
}

\author{
Lisa Kiely ${ }^{1}$, Keshav Parajuly ${ }^{2,3 *}$, James A. Green ${ }^{4}$ and Colin Fitzpatrick ${ }^{2}$ \\ ${ }^{1}$ Castletroy College, Limerick, Ireland, 2 Department of Electronic and Computer Engineering, University of Limerick, Limerick, \\ Ireland, ${ }^{3}$ Sustainable Cycles Programme (SCYCLE), United Nations University, Vice Rectorate in Europe, Bonn, Germany, \\ ${ }^{4}$ School of Allied Health and Physical Activity for Health, Health Research Institute, University of Limerick, Limerick, Ireland
}

\section{OPEN ACCESS}

Edited by:

Mariale Moreno,

Lisboa, Portugal

Reviewed by:

Kiriaki M. Keramitsoglou,

Democritus University of

Thrace, Greece

Yusuke Kishita

The University of Tokyo, Japan

*Correspondence:

Keshav Parajuly

parajuly@vie.unu.edu

Specialty section:

This article was submitted to

Circular Economy,

a section of the journal

Frontiers in Sustainability

Received: 05 December 2020 Accepted: 09 February 2021

Published: 01 March 2021

Citation:

Kiely L, Parajuly K, Green JA and Fitzpatrick C (2021) Education for UN Sustainable Development Goal 12: A

Cross-Curricular Program for Secondary Level Students.

Front. Sustain. 2:638294.

doi: 10.3389/frsus.2021.638294
Dealing with complex sustainability challenges requires an integrated approach to thinking and hence learning. Well-designed, integrated sustainability educational programs at the school level can have a significant positive impact on sensitizing students in this area. We present the case of a cross-curricular educational program designed and implemented at secondary level school with a focus on sustainability of material resources used in electronic products-a fast-growing sector with a significant environmental footprint. Over a 4-week period, teachers of five subjects (science, geography, business, technology and civic, social and political education) tailored their classes to focus on the topic of critical raw materials as it relates to these subjects. Examining a control group against the intervention group before and after the program, we use the New Ecological Paradigm (NEP) scale as a measure of students' environmental beliefs in order to find out the extent to which the program helped the cohort of students develop and retain such an ecological paradigm. Students' pro-NEP improved after the program, including on several facets, such as belief in limits to growth. Findings suggest that our crosscurricular approach was able to influence the young students' environmental orientation in a desirable direction.

Keywords: SDG 12, sustainable consumption and production, sustainability education, critical raw materials, new ecological paradigm, consumer electronics

\section{INTRODUCTION}

The complex nature of sustainability challenges demands an equally integrated approach to tackling them. Ensuring sustainable development will require fundamental changes to the extent of renewing our economic system that operates between social and planetary boundaries (Stahel, 2016; Raworth, 2017). This insight, which should ideally be a fundamental operating principle and a common knowledge, however, is mostly limited to researchers and practitioners of some niche disciplines. The awareness of sustainability issues among other professionals and the general population is rather abstract, which fails to translate easily into actionable items (Bosselmann, 2001). This keeps individuals from contributing in their capacity as policy makers, in the private sector, or consumers. Enabling people through education and other campaigns to make such positive contributions is therefore crucial in ensuring global sustainability (Independent Group of Scientists appointed by the Secretary-General, 2019). 
Education's role is not only teaching job skills, but also developing analytical and creative capacities for addressing social, ecological, and economic issues in different dimensions of sustainable development (UNESCO, 2016). Early education shapes individuals' worldview that will have a lifelong influence on their role as a professional in any given sector. Educational attainment also stands out as the strongest predictor of awareness about climate change issues (Lee et al., 2015). Furthermore, access to quality education itself is a sustainable development goal, which also serves as an opportunity to influence on topics such as global sustainability (O’Neill et al., 2020). Besides developing young individuals' professional capabilities, environmental education can also serve as a behavioral intervention, which helps them to become responsible consumers. Students participating in educational interventions can even foster environmental concerns among their parents (Boudet et al., 2016). A quality scientific dissemination could therefore be an important investment in order to change environmental orientation especially among school-aged children (Barradas and GhilardiLopes, 2020).

The recent wave of climate protests by millions of peopleespecially amongst young students-across the globe suggests an increased recognition of environmental problems. In contrast to this wave are "misinformation campaigns" seeking to undermine scientific consensus and limit societal engagement with climate issues (van der Linden et al., 2017). The relevance of sciencebased education campaigns, which are at the forefront of intervention strategies when it comes to promoting a proenvironmental worldview, appears to be more important than ever. The strong prospect of interdisciplinary climate change education has been recognized for students at university level (McCright et al., 2013) where sustainability education for future engineers and scientists, or even the availability of "sustainability degrees" is increasingly becoming common (Mascarelli, 2013). At the school level however, sustainability education is still in its initial phase with clarity lacking in terms of concept, structure, and administration of an effective program (Warner and Elser, 2014).

Sustainability education can be broadly defined as a means of generating solution-based knowledge that can help in the transition toward a more sustainable future (Warner and Elser, 2014). The traditional "environmental education" is shifting toward "sustainable education," which is about understanding not only the natural environments, but also the humannature relationship (Bosselmann, 2001). As a growing number of education institutions introduce sustainability education programs, a patchwork of concepts, curricula, intervention, and evaluation metrics have evolved but there is a long way to go. There are two key challenges to this.

First, despite several innovative approaches and policy support, realization of transformative programs of education for sustainable development from their theory to real life implementation is constrained in traditional pedagogies setups (Cotton et al., 2009). Although a variety of environmental education programs exist, there is a need for a more diversified approach (Ardoin et al., 2017). Cross-cutting competenciesbeyond specific competencies needed to tackle context-specific problems-are key to achieving sustainable development and should be considered in educational activities for all ages (Rieckmann, 2017). Education for sustainability can be effective neither by a mere introduction of generic environmental knowledge alone nor by the advocacy of environmentalism without fundamental intellect. And even fundamental knowledge cannot be complete with a monodiscipline approach preoccupied by traditional narratives of sustainability (Bosselmann, 2001). In order to address the complex and multidisciplinary nature of sustainability issues, education programs should build on the expertise of multiple educators whose contributions collectively result in a multidisciplinary approach that may not be achieved by one educator offering knowledge on multiple disciplines.

Second, although sustainability education initiatives are growing, institutions lack formal processes and the necessary resources to evaluate the impacts of their programs. The true effectiveness of an educational program in terms of influencing people's behavior cannot be easily derived. In particular, it is more difficult to measure change in students' affective attributes compared to their knowledge and skill sets resulting from an educational intervention (Harraway et al., 2012). Measuring these changes is important to be able to analyze impacts of these programs. Educational institutions often lack sufficient resources to design and evaluate sustainability educational programs. Especially at the school level, where the curriculum is more rigid, such educational programs are often ad-hoc and depend on external funding. And since secondary-level teachers are not expected to be involved in scientific research activities, they may not be fully updated on recent developments concerning burning sustainability issues.

In this context, we illustrate how a collaboration between a secondary-level school and a university can be instrumental in developing a comprehensive educational program on one specific sustainability issue. The two key objectives of this paper are to (a) document the design and implementation of a transdisciplinary sustainability education program and (b) illustrate an efficient evaluation of the education program to measure its efficacy. We present a case of cross-curricular approach for an education program at a secondary level focusing on UN Sustainable Development Goals 12: "Ensure sustainable consumption and production patterns." In particular, we address Target 12.8 that focuses on public availability of information and awareness for sustainable development through mainstreaming of education for sustainable development for students as well as teachers. We designed and implemented a sustainability education program with a focus on electronic products and material resources at a secondary level school based in Ireland. We also document a swift evaluation of the education program using a pre-existing methodology to measure the effectiveness of the educational intervention. Thus, we are able to address two key stages of the educational program cycle: designing and implementing programs built on current science and evaluating the impacts of such programs in an efficient manner.

The use of information and telecommunication technology is widespread among young populations in the European Union with $95 \%$ of $16-19$ years old using the internet on a daily basis 
TABLE 1 | Number of participant students in the control and intervention groups with gender and age breakdown.

\begin{tabular}{lcc}
\hline Gender & Control group & Intervention group \\
\hline Males & 93 & 114 \\
Females & 116 & 97 \\
Age & & \\
12 & 45 & 47 \\
13 & 158 & 161 \\
14 & 5 & 3 \\
15 & 1 & \\
\hline
\end{tabular}

(Eurostat, 2020). A longitudinal study among students in Ireland reported mobile phone ownership of $40 \%$ at the age of nine and $98 \%$ at 13 (Dempsey et al., 2018). These figures highlight the importance of awareness about the sustainable production and consumption of electronic products among today's young populations who are using electronic products early on compared to their predecessors. The use of electronic products comes with its own set of environmental as well as social and human health issues (Parajuly et al., 2019). The sustainability concerns about electronic products are also linked to the use of critical metal resources in them, which is not well-known among the general population. While environmental impacts linked to some sectors including food, transport, and energy are becoming more common knowledge, sustainability issues of material resources used in everyday products such as electronics is less known. This issue is the focus of our educational program E-Mining@School, which we present here as our case.

\section{METHODS}

The cross-curricular educational program E-mining@School consisted of a series of lessons with a focus on the topic of critical raw materials for a period of 4 weeks. As part of the evaluation of the program, we administered in-person surveys using the questionnaire consisting of the $15 \mathrm{New}$ Ecological Paradigm (NEP) (Dunlap, 2008) scale items designed to collect responses in a 5-point Likert scale with options of strongly disagree, disagree, neutral, agree, and strongly agree. We assigned two student groups as control and intervention groups. Within each group, we surveyed half the students before the delivery of the E-Mining@School program and the other half afterwards. In total, 420 students participated in the education program and the survey. Table 1 below summarizes the gender and age of the participants in the control and intervention groups.

\section{E-Mining@school}

The E-Mining@School program was run at Castletroy College, which is a secondary level school based in Limerick, Ireland. A suburb of Limerick City with a population of almost 15,000 people, Castletroy is characterized by significant numbers of residents having high educational attainment and employment in professional, managerial, and skilled occupations. According to the 2016 census, it has an unemployment rate of $3 \%$, which is half the national average. Castletroy College is a public secondary school of over 1,200 students with an enrolment policy that gives strong priority to people living within the locality with a mission to provide a holistic education of the individual, enabling students to become responsible, caring members of society as well as encouraging them to reach their full potential.

Secondary level education in Ireland is going through a major transition with the introduction of the new Junior Cycle program. A major change for subject teachers as they moved from the Junior Certificate (1989) to the Junior Cycle (2015) was a move from a content-driven syllabus to a learning outcomes-based specification. Each Junior Cycle subject specification consists of a series of learning outcomes. Subject teachers are encouraged to plan units of work to include several learning outcomes to give students a deeper understanding of the relationships and connections that exist between various elements of each subject specification. The learning outcomes are broad and non-specific which gives teachers a degree of autonomy and flexibility to decide how best to ensure students achieve the intended learning.

In March 2018, a team from the University of Limerick approached Castletroy College looking for a partner for the E-Mining@School project under the European EIT Raw Materials initiative in order to design and deliver an educational package aimed to raise awareness among students about critical raw materials in e-waste. This coincided with the ongoing unit planning in the area of sustainability within subject departments in the school. Therefore, it was an opportune time for teachers across a number of subject departments to come together and design a unit of work on the areas of sustainability with the support of a research group and experts in the area from the university on the common theme of critical raw materials. Students learning about sustainability in their use of smartphones from the perspective of the different subject specifications would enable students to make meaningful and progressively more challenging connections between learning in different subjects.

Unit planning commenced in September 2018 with members of the core design team meeting regularly in their free time, during lunch or during times allocated by school management. The process took the following steps:

1. Each subject area identified several learning outcomes that could be used to link around the topic of electronics and sustainability.

2. Input was sought from the university on the area of critical raw materials. This subject matter was new to most members of the team and expertise was required to ensure common understanding of the topic as a whole.

3. Each subject department identified learning intentions related to the area of critical raw materials that would outline the intended learning in each of our learning outcomes.

4. Once the key learning was agreed in each of the subject areas, the team looked for common themes and arranged the learning on a weekly thematic basis.

5. Teachers then designed a range of student-centered lessons, which included learning activities that afforded students to take ownership and responsibility of their learning and that 
TABLE 2 | Overview of learning outcomes for subjects over the course of the E-Mining@School project.

\section{Science}

Week 1

- Define the term element, mixture and compounds, metals and non-metals, and list their properties

- Explain how the elements used in mobile phones have changed over the past decade

- Work in groups to plan, design, and carry out an investigation to determine if a material is an insulator or conductor of heat and electricity

Week 2

- Introduce and discuss the concept of critical raw materials

- Identify raw materials that are essential in manufacture of smartphones

- Research and prepare a poster for presentation on one critical raw material

Week 3 - Define energy and identify five different forms of energy

- Calculate the energy used while carrying my mobile phone

- Identify what my phone needs to interact with in order to function

- Working in groups, analyse data from our student survey and identify patterns and trends in our phone use

Week 4

- Appreciate the scale and impact of electronic waste and the dangers of human toxicity Identify and list the advantages and disadvantages of our current systems for dealing with electronic waste

- Discuss roles that can be taken to help organize an e-waste collection event

\section{Geography}

Week 2

Week 3

Week 4
- Identify how natural resources can be extracted from the earth Discover where resources can be found around the world

- Describe the process of drilling, shaft mining, and quarrying

- Identify the advantages and disadvantages of quarrying

- Identify uses of cobalt Compare how cobalt is extracted in the Democratic republic of Congo to how zinc is extracted in Navan, County Meath, Ireland

- Understand how natural gas is exploited in Ireland, and begin to understand how the exploitation of resources can become controversial over time

Civics, Social, and Political Education (CSPE)

Week 1

- Use the definition of sustainable development created in CSPE class and apply it to the exploitation of natural resources

- Identify ways in which exploited mines can be used sustainably

- Consider a variety of definitions of development and devise their own definition of sustainable development

- Introduction to the UN Sustainable Development Goal 12: Ensure sustainable consumption and production patterns

- Understand the term ecological footprint

Week 2

- Identify how SDG 12 can be linked to the issue of critical raw materials

- Analyse a global issue: unsustainable consumption and production of critical raw materials

Week 3

- Identify the impacts of electronic waste and discover how electronic waste impacts on the lives of people in Ghana and China

- Compare and analyse information

- Identify possible solutions to the challenge of unsustainable consumption of CRMs

Week 4

- Evaluate how can I contribute to a more sustainable consumption and production of critical raw materials

- Identify waste materials in my environment that I can bring to the waste recycling event

- Work as part of a team to organize a waste collection event

Business

Week 1

- Explain the term "economic resources"

- Identify and explain each of the factors of production

- Explain the term scarcity

- Be able to distinguish between needs and wants

- Explain how scarcity, choice, and opportunity costs for individuals, companies, and governments

Week 2

- Discuss and compare economic systems Centrally planned e.g., China, free market, USA, and mixed economy, Ireland

- Understand different sectors of the economy and identify the sectors that recycling companies work in Explain how the different sectors interact

Week 3 - Explain and distinguish between a closed economy and an open economy

- Outline the importance of imports and exports for a country

- Understand the factors of production. Begin to understand the importance of the government recognizing the sustainability of resources

Week $4 \quad$ - Understand factors affecting demand and factors affecting supply

- Understand a business plan and its importance to business

- Understand the importance of sustainability

- Discuss ethical business behaviors. Explain the term marketing. Explain the reasons for advertising. Plan for the marketing and advertising of the e-waste collection event

\section{Engineering}

Week 2

\section{Break it down}

- Explain how design impacts on the function and quality of a product

- Examine modern technologies, how they are designed and manufactured

- Look at the role of CRMs in modern technologies

- Students analyse the impact a disruption in supply of CRMs would have on the production of modern technologies 
TABLE 2 | Continued

\begin{tabular}{ll}
\hline Week 3 & Pick it apart \\
& - Examine products design intent \\
& - Assess a product's intended life cycle \\
& - Evaluate the sustainability of a products design \\
& - Students will compare products with differing intended life cycles and discuss the sustainability of each \\
& Build it up \\
Week 4 & - Design a new product concept with a more sustainable life cycle
\end{tabular}

would develop a range of key skills as outlined by the junior cycle framework.

6. Opportunities for students to reflect on their learning and in how they learn were deliberately embedded in the design of the module with the inclusion of a student learning log. Here students were able to identify the key learning in each of the subjects per week as well as facilitated to make connections between the learning in each of the different subject areas.

Once the teacher design team understood the topic of critical raw materials, it was then broken down as specific learning in each of the five subject areas that would achieve the learning outcomes in each of the subject specifications. The overview of learning outcomes for each subject area is detailed in Table 2.

Input and feedback had been sought from the wider delivery team numerous times during the design phase so that the rationale was clear and understood by all and all teachers felt a degree of ownership of the final product. After the unit outline had been agreed upon and lesson plans and resources designed, it was handed over to a wider team of delivery teachers. There are seven base classes in each group so a team of over 20 teachers were required to deliver the unit to all base classes in each of the five subject areas. More than 210 second year students were taught this interdisciplinary unit over 4 weeks during a pilot in January/February 2019 and again in full in January/February 2020. Figure 1 illustrates the of project delivery design and photos from E-mining@School project activities.

A Google Classroom for the teacher design and delivery teams was set up to share all resources as well as to ensure good communication and sharing of ideas, progress, and challenges before, during, and after delivery. The unit was delivered over a 4-week period and students were encouraged to complete a learning $\log$ at the end of each week. This ensured that classroom activities and strategies that worked well were logged, and connections that students made between learning each of the subject areas were identified. These reflections would form the basis of the evaluation of the unit at the end of delivery.

\section{The NEP Scale}

The NEP scale is a well-established measure of proenvironmental orientation, which has been used by social-psychological models to predict people's environmental concerns, attitudes and behaviors (Dunlap et al., 2000; Dunlap, 2008). It has been used as a tool to measure environmental beliefs or worldviews, which to some degree indicate environmental attitude and behaviors of people. The NEP scale has been previously used, for example, in the context of coastal and marine environments (Barradas and Ghilardi-Lopes, 2020) and sustainable built environment (Balador et al., 2020). To our best knowledge, this is the first use of the NEP scale in the context of electronic products and material resources to study the effectiveness of a cross-curricular approach to sustainability education.

The NEP scale consists of following 15 items (with eight proNEP and seven anti-NEP items) that provide "a comprehensive coverage of key facets of an ecological worldview:"

1. We are approaching the limit of the number of people the earth can support

2. Humans have the right to modify the natural environment to suit their needs

3. When humans interfere with nature it often produces disastrous consequences

4. Human ingenuity will insure that we do not make the earth unliveable

5. Humans are severely abusing the environment

6. The earth has plenty of natural resources if we just learn how to develop them

7. Plants and animals have as much right as humans to exist

8. The balance of nature is strong enough to cope with the impacts of modern industrial nations

9. Despite our special abilities humans are still subject to the laws of nature

10. The so-called "ecological crisis" facing humankind has been greatly exaggerated

11. The earth is like a spaceship with very limited room and resources

12. Humans were meant to rule over the rest of nature

13. The balance of nature is very delicate and easily upset

14. Humans will eventually learn enough about how nature works to be able to control it

15. If things continue on their present course, we will soon experience a major ecological catastrophe

These items can be summed together for an overall NEP scale, combined into pro-NEP (odd-numbered items) and antiNEP '(even-numbered items) subscales or into five facets that influence the ecological worldview: the reality of limits to growth $(1,6,11)$, anti-anthropocentrism $(2,7,12)$, the fragility of nature's balance $(3,8,13)$, rejection of exceptionalism $(4,9,14)$, and possibility of an ecocrisis $(5,10,15)$.

Student groups from different class years were assigned as control and intervention groups. Within each year group, half the classes were surveyed before the delivery of the EMining@School program in January 2020 and the other half were 


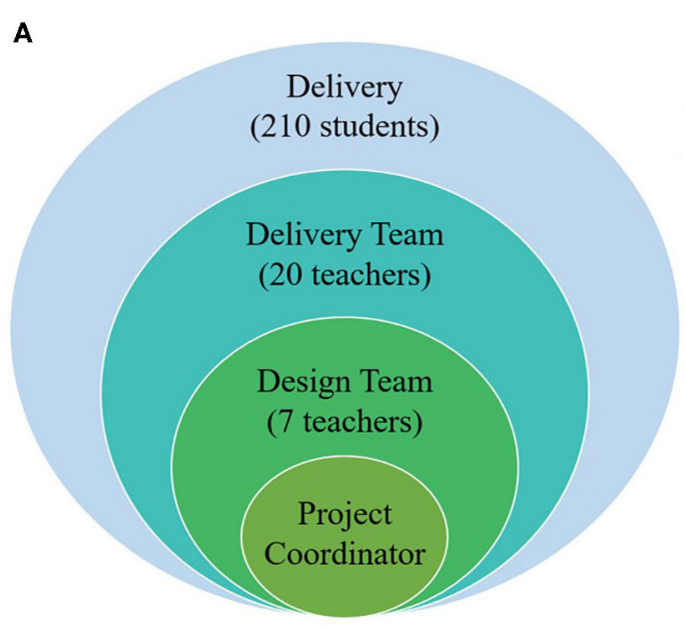

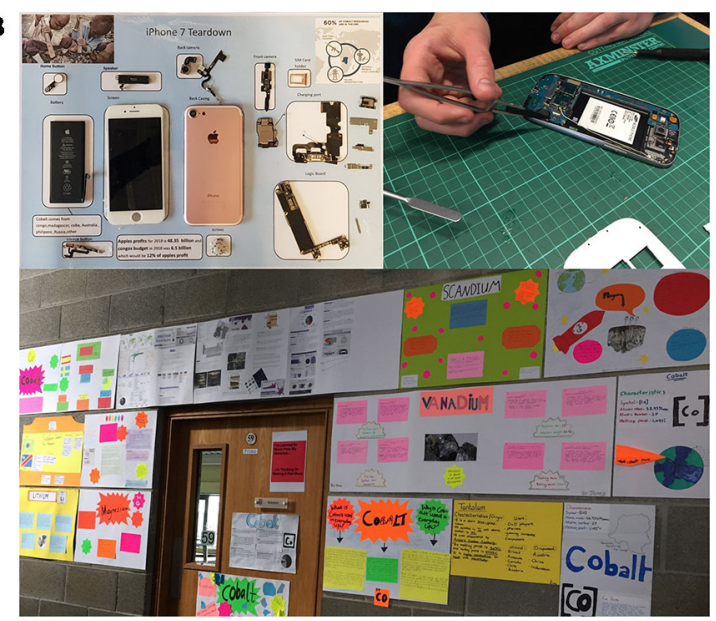

FIGURE 1 | Project delivery design (A) and E-mining@School project activities (B).

surveyed afterwards in February 2020. The survey took place in a supervised computer room without reference being made to the survey being in connection with the E-Mining@School program.

Each of the NEP (sub)scales (overall NEP, pro-NEP, anti-NEP, reality of limits to growth, anti-anthropocentrism, the fragility of nature's balance, rejection of exceptionalism, and possibility of an ecocrisis) is reported as a Percentage of Maximum Possible (POMP) score (Cohen et al., 1999). This means that independent of the number of items comprising the scale, 100 always represents the maximum score and 0 represents the minimum score, with 50 being the midpoint, and so forth. Cohen's $\mathrm{d}$ is reported as a measure of effect size. Unpaired $t$ tests are used to examine change before and after the education intervention within the group, and a two (control, intervention) by two (before, after) between-subjects ANOVA is used to test for differences. As discussed in the limitations later, measuring the same students before and after the education program would have produced a measure of within-individual change.

\section{RESULTS AND DISCUSSION}

Figure 2 shows the mean POMP scores for each of the (sub)scales as a function of time (before, after) and condition (control, intervention). For the students in the intervention, their mean increased for all NEP scales-including proNEP scales-and decreased on the anti-NEP scale. These differences were significant for the pro-NEP items, $t(159)=$ 2.01, $p=0.046, d=0.32$, Reality of Limits to Growth, $t(159)=2.22, p=0.028, d=0.35$, and Rejection of Exceptionalism, $t(159)=2.82, p=0.005, d=0.44$. In contrast, no change between before and after was significant in the control classes. An interaction test (that there is a difference in the observed differences) was significant for Rejection of Exceptionalism, $F(1,360)=9.04, p=0.003$, and Possibility of an Ecocrisis, $F(1,360)=5.29, p=0.02$. These appear as crossover patterns, where the more ecological perspective increased in the intervention condition but declined in the control condition.

Some dimensions of the NEP scale were also more or less broadly agreed with overall, irrespective of time or condition. Recall that a POMP score of 100 would mean that all students strongly agreed with each item within a scale, and that 50 means, on average, a midpoint score for each statement. Students had higher pro-NEP scores $(M=70.1, \mathrm{SD}=14.9)$ than anti-NEP scores $(M=49.4, \mathrm{SD}=14.2)$. However, they were less likely to agree with the Reality of Limits to Growth $(M=50.2, \mathrm{SD}=$ $15.3)$ and Rejection of Exceptionalism $(M=52.0, \mathrm{SD}=14.0)$. In contrast, the Possible Existence of an Ecocrisis was most strongly endorsed $(M=71.7, \mathrm{SD}=18.3)$, with reasonable support for the Fragility of Nature's Balance $(M=65.8, \mathrm{SD}=14.0)$ and Anti-anthropocentrism $(M=65.2, \mathrm{SD}=19.5)$.

The NEP scale has been mostly used in the past to study the correlation between respondents' ecological orientation and their sociodemographic characteristics. Use of this technique with control experiments to measure changes in ecological orientation of an intervention is rare. Previous studies have reported an overall trend of respondents endorsing pro-ecological beliefs on all NEP scale items, however, this being truer for items reflecting on the "fragility of nature's balance" and less true for items suggesting the idea of "limits to growth" (Dunlap et al., 2000). This pattern is also present in our findings with the large majority in all groups endorsing the "balance of nature" idea and accepting the "possibility of eco-crisis." However, the endorsement is mixed in the case of "limits to growth" and "rejection of exceptionalism." One possible interpretation of this is that students are optimistic about the capacity of science and technology to solve some of these problems. Previous studies have also reported similar findings on the widespread existing belief that humans can intelligently exploit natural resources and solve environmental problems (Sousa et al., 2016).

People with a "pro-environmental worldview" are more likely not only to be concerned about environmental problems but also to take action to address these problems (Xue et al., 


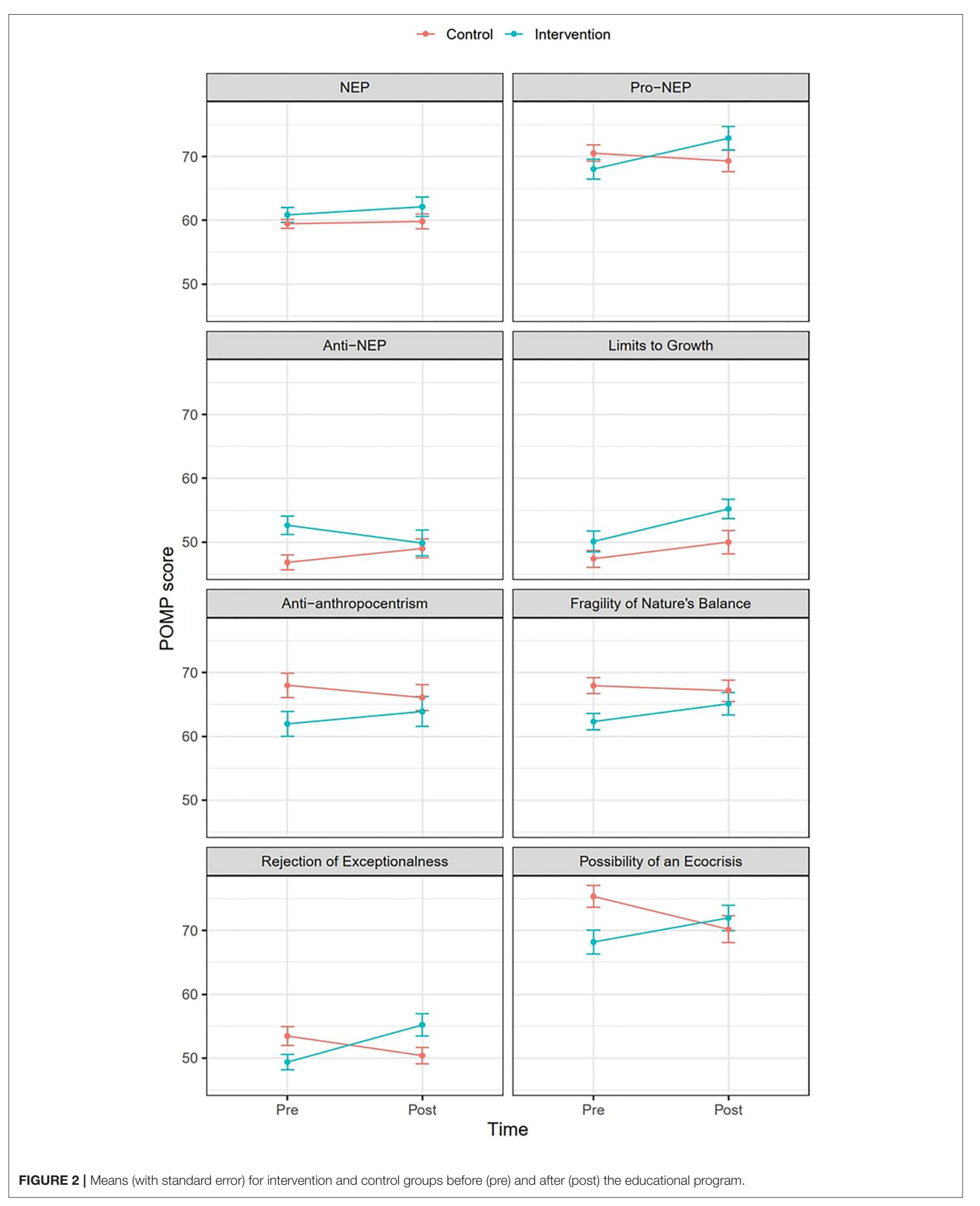


2016). Environmental education, short and long, can help the younger generation to develop and retain such an ecological paradigm. However, most educational programs focus on the pro-environmental behavioral changes of students as the outcome of an educational intervention. Immediate changes resulting from short-term educational interventions are usually very small, which makes it difficult to document the effectiveness of such programs. Our approach was aimed at, on top of potential behavioral change related to everyday consumption, a longer-lasting set of sustainability skills that students could potentially use in future as professionals. Educating students as designers and enablers of the future production and consumption systems-and not merely as consumers-can have lasting impacts. Traditional approach to "environmental education" leans more toward "preservation" of local nature. In a globalized economy and ever-growing consumption of new products, a more "holistic" approach is needed. Educational approaches focused on values only may be less effective without teaching students also about economic and technological tools that they can use to implement what they learn. Environmental attitudes may not always directly translate into pro-environmental behavior as there are several other internal and external factors coming to play (Parajuly et al., 2020). One-time interventions can only have a small effect, therefore, continuous education throughout the school years focusing on multiple dimensions of sustainability may produce a reasonable change in young students' environmental orientation.

A limitation of our study has been that the controlled experiment in our study could not control for the possibilities of the student coming across other learning opportunities besides the educational intervention during the 4 -week period between two surveys. It cannot be ruled out that some of the studentsproactively or not-gathered more information through news, social media, and other sources. Analytically, the analysis could have been strengthened if we had recorded students' class membership, and nested their observations within classes, as well as linking student responses before and after, enabling a withinperson measure of change. Besides the educational program, we had originally planned an "engagement program" for the students. The program included organization and participation of the students in an e-waste collection event in which residents of the local community would bring their end-of-life electronics for proper collection in order to facilitate recycling. Ideally, we could have surveyed the students again at the end of the engagement program and studied those responses as well. However, such an event did not materialize because of the COVID-19 situation.

The NEP scale is sometimes criticized for being outdated, oversimplified and for not being able to accurately predict environmental behaviors and alternatives such as the Environmental Attitudes Inventory is proposed to address these limitation (AlMenhali et al., 2018). The findings from the NEP studies should therefore be cautiously interpreted. On the other hand, however, the NEP scale has been praised for its "novelty" as a tool that covers a broad spectrum of ecological viewpoints while prompting responses in Likert-scale form that can be used worldwide without the need for reflection or comparison (Ntanos et al., 2019). In our opinion, the simplicity makes NEP a suitable tool in settings such as ours where we are measuring teenager's behavioral attitudes to have a glimpse into their state of environmental orientation. Other tools such as the "Attitude toward Sustainable Development" scale proposed by Biasutti and Frate (2016) that are based on measuring multiple dimensions of environment, economy, society, and education, can be tested in similar settings in future works in order to investigate students' sustainability attitudes and their relation to other variables.

\section{CONCLUDING REMARKS}

Among the growing concerns of climate change and lack of actions to produce visible changes, the importance of early sustainability education is becoming more important than ever in school education. In order for these educational interventions to be effective, it has to be more than theoretical knowledge on environmental protection. Practical lessons linked to real-life sustainability problems may be an effective way to strengthen environmental awareness of young pupils. We document a comprehensive, cross-disciplinary second level educational intervention focusing on sustainable material consumption. To our knowledge, this is a first of its kind educational program. It serves as a model for future programs seeking not only to raise awareness among young populations, but also to equip them with tools for designing solutions for sustainability challenges. Achieving the ambitious SDGs will require collaboration across sectors and disciplines at various levels. We offer an example of how educational institutions from different levels can work together to address the complex challenge of sustainable consumption and production under the UN SDG12.

We also illustrate an example of how education programs can be evaluated for their effectiveness by comparing the change in students' environmental orientation between control and intervention groups. The impacts of the intervention were evaluated by measuring students' ecological paradigm using the well-established NEP-scale. Future works can build upon this approach in order to test and enhance this technique tailored to different educational contexts. Our finding suggests a consistently incremental and some significant changes in the environmental orientation of the students in the desired direction. For the increased robustness of the evidence, future research may also focus on tracking the impact of the intervention on individual students.

\section{DATA AVAILABILITY STATEMENT}

The raw data supporting the conclusions of this article will be made available by the authors, without undue reservation.

\section{AUTHOR CONTRIBUTIONS}

LK and CF led the design and implementation of the E-Mining@School program as well as the administration of the survey. JG led the data analysis. KP developed the paper with contributions from all co-authors. All authors contributed to the article and approved the submitted version. 


\section{FUNDING}

This work was part of the Behavioral Change for the Circular Economy (BC4CE) project, which received funding from the Irish Research Council and from the European Union's Horizon 2020 research and innovation program under the Marie Skłodowska-Curie grant agreement No. 713279. The E-Mining@School project received funding from EIT Raw Materials (Project number 17144).

\section{ACKNOWLEDGMENTS}

The authors would like to acknowledge the work of Sharon Delaney, Kevin Grant, Linda Hannon, John Keehan, Ann-Marie

\section{REFERENCES}

AlMenhali, E. A., Khalid, K., and Iyanna, S. (2018). Testing the psychometric properties of the Environmental Attitudes Inventory on undergraduate students in the Arab context: a test-retest approach. PLoS ONE 13:e0195250. doi: 10.1371/journal.pone.0195250

Ardoin, N. M., Bowers, A. W., Roth, N. W., and Holthuis, N. (2017). Environmental education and K-12 student outcomes: a review and analysis of research. J. Environ. Educ. 49, 1-17. doi: 10.1080/00958964.2017.13 66155

Balador, Z., Gjerde, M., Vale, B., and Isaacs, N. (2020). Towards a better understanding of people's underlying ecological worldviews in New Zealand. Environ. Dev. Sustain. 23, 1087-1103. doi: 10.1007/s10668-020-00600-9

Barradas, J. I., and Ghilardi-Lopes, N. P. (2020). A case study using the New Ecological Paradigm scale to evaluate coastal and marine environmental perception in the Greater São Paulo (Brazil). Ocean Coast. Manag. 191:105177. doi: 10.1016/j.ocecoaman.2020.105177

Biasutti, M., and Frate, S. (2016). A validity and reliability study of the attitudes toward sustainable development scale. Environ. Educ. Res. 23, 214-230. doi: 10.1080/13504622.2016.1146660

Bosselmann, K. (2001). University and Sustainability: compatible agendas? Educ. Philos. Theory 33, 167-186. doi: 10.1111/j.1469-5812.2001.tb00261.x

Boudet, H., Ardoin, N. M., Flora, J., Armel, K. C., Desai, M., and Robinson, T. N. (2016). Effects of a behavior change intervention for Girl Scouts on child and parent energy-saving behaviors. Nat. Energy 1:16091. doi: 10.1038/nenergy.2016.91

Cohen, P., Cohen, J., Aiken, L. S., and West, S. G. (1999). The problem of units and the circumstance for POMP. Multivariate Behav. Res. 34, 315-346. doi: 10.1207/S15327906MBR3403_2

Cotton, D., Bailey, I., Warren, M., and Bissell, S. (2009). Revolutions and secondbest solutions: education for sustainable development in higher education. Stud. High. Educ. 34, 719-733. doi: 10.1080/03075070802641552

Dempsey, S., Lyons, S., and McCoy, S. (2018). Later is better: mobile phone ownership and child academic development, evidence from a longitudinal study. Econ. Innov. New Technol. 28, 798-815. doi: 10.1080/10438599.2018.1559786

Dunlap, R. E. (2008). The new environmental paradigm scale: from marginality to worldwide use. J. Environ. Educ. 40, 3-18. doi: 10.3200/JOEE.40.1.3-18

Dunlap, R. E., Van Liere, K. D., Mertig, A. G., and Jones, R. E. (2000). New trends in measuring environmental attitudes: measuring endorsement of the new ecological paradigm: a revised NEP scale. J. Soc. Issues 56, 425-442. doi: 10.1111/0022-4537.00176

Eurostat (2020). Individuals-Frequency of Internet Use (code: isoc_ci_ifp_fu). Luxembourg City: Eurostat.

Harraway, J., Broughton-Ansin, F., Deaker, L., Jowett, T., and Shephard, K. (2012). Exploring the use of the revised new ecological paradigm scale (NEP) to monitor the development of students' ecological worldviews. J. Environ. Educ. 43, 177-191. doi: 10.1080/00958964.2011.634450
McMahon and Marian Roche (Core Design Team for Castletroy College), and all of the teachers who delivered the lessons. We also acknowledge the leadership of the School Principal, Padraig Flanagan, and Jude Sherry (UL) for her research support to the teachers. We would also like to recognize the guidance received from the inspectorate and JCT as part of the Department of Education and Skills (DES) STEP UP Project with special thanks to Siobhán Broderick, Sinéad Touhy, David King, Áine Woods, and James Thompson.

\section{SUPPLEMENTARY MATERIAL}

The Supplementary Material for this article can be found online at: https://www.frontiersin.org/articles/10.3389/frsus. 2021.638294/full\#supplementary-material
Independent Group of Scientists appointed by the Secretary-General (2019). Global Sustainable Development Report 2019: The Future is Now-Science for Achieving Sustainable Development. New York, NY: United Nations. Available online at: https://sustainabledevelopment.un.org/content/documents/ 24797GSDR_report_2019.pdf (accessed December 5, 2020).

Lee, T. M., Markowitz, E. M., Howe, P. D., Ko, C.-Y., and Leiserowitz, A. A. (2015). Predictors of public climate change awareness and risk perception around the world. Nat. Clim. Change 5, 1014-1020. doi: 10.1038/nclimate2728

Mascarelli, A. (2013). Sustainability: environmental puzzle solvers. Nature 494, 507-509. doi: 10.1038/nj7438-507a

McCright, A. M., O’Shea, B. W., Sweeder, R. D., Urquhart, G. R., and Zeleke, A. (2013). Promoting interdisciplinarity through climate change education. Nat. Clim. Change 3, 713-716. doi: 10.1038/nclimate1844

Ntanos, S., Kyriakopoulos, G., Skordoulis, M., Chalikias, M., and Arabatzis, G. (2019). An application of the new environmental paradigm (NEP) scale in a greek context. Energies 12:239. doi: 10.3390/en12020239

O’Neill, B. C., Jiang, L., Kc, S., Fuchs, R., Pachauri, S., Laidlaw, E. K., et al. (2020) The effect of education on determinants of climate change risks. Nat. Sustain. 3, 520-528. doi: 10.1038/s41893-020-0512-y

Parajuly, K., Fitzpatrick, C., Muldoon, O., and Kuehr, R. (2020). Behavioral change for the circular economy: a review with focus on electronic waste management in the EU. Resour. Conserv. Recycl. X 6:100035. doi: 10.1016/j.rcrx.2020.100035

Parajuly, K., Kuehr, R., Awasthi, A.K., Fitzpatrick, C., Lepawsky, J., Smith, E., et al. (2019). Available online at: https://collections.unu.edu/eserv/UNU:7440/ FUTURE_E-WASTE_SCENARIOS_UNU_190829_low_screen.pdf (accessed December 5, 2020).

Raworth, K. (2017). A doughnut for the Anthropocene: humanity's compass in the 21st century. Lancet Planet. Health 1, e48-e49. doi: 10.1016/S2542-5196(17)30028-1

Rieckmann, M. (2017). Education for Sustainable Development Goals: Learning Objectives. Paris: UNESCO Publishing.

Sousa, E., Quintino, V., Palhas, J., Rodrigues, A. M., and Teixeira, J. (2016). Can environmental education actions change public attitudes? an example using the pond habitat and associated biodiversity. PLOS ONE 11:e0154440. doi: 10.1371/journal.pone.0154440

Stahel, W. R. (2016). The circular economy. Nature 531:435. doi: 10.1038/531435a UNESCO (2016). Incheon Declaration and Framework for Action for the Implementation of Sustainable Development Goal 4. Available online at: http:// uis.unesco.org/sites/default/files/documents/education-2030-incheon-framew ork-for-action-implementation-of-sdg4-2016-en_2.pdf (accessed December 5, 2020).

van der Linden, S., Leiserowitz, A., Rosenthal, S., and Maibach, E. (2017). Inoculating the public against misinformation about climate change. Glob. Chall. 1:1600008. doi: 10.1002/gch2.201600008

Warner, B. P., and Elser, M. (2014). How do sustainable schools integrate sustainability education? an assessment of certified sustainable K-12 schools in the United States. J. Environ. Educ. 46, 1-22. doi: 10.1080/00958964.2014.953020 
Xue, W., Marks, A. D. G., Hine, D. W., Phillips, W. J., and Zhao, S. (2016). The new ecological paradigm and responses to climate change in China. J. Risk Res. 21, 323-339. doi: 10.1080/13669877.2016.1200655

Conflict of Interest: The authors declare that the research was conducted in the absence of any commercial or financial relationships that could be construed as a potential conflict of interest.
Copyright (C) 2021 Kiely, Parajuly, Green and Fitzpatrick. This is an open-access article distributed under the terms of the Creative Commons Attribution License (CC $B Y)$. The use, distribution or reproduction in other forums is permitted, provided the original author(s) and the copyright owner(s) are credited and that the original publication in this journal is cited, in accordance with accepted academic practice. No use, distribution or reproduction is permitted which does not comply with these terms. 